Sharif University of Technology
Scientia Iranica
Transactions E: Industrial Engineering
hCIENTIA

\title{
Partnership of contractors in cooperative game theory approach to project resource management
}

\author{
M. Akhbari* \\ Department of Industrial Engineering, Electronic Branch, Islamic Azad University, Tehran, Iran.
}

Received 15 January 2018; received in revised form 6 June 2018; accepted 25 August 2018

\author{
KEYWORDS \\ Transferable utility \\ cooperative game; \\ Partnering; \\ Renewable resource \\ allocation; \\ Net Present Value \\ (NPV); \\ Stability analysis; \\ Project scheduling \\ problem.
}

\begin{abstract}
It is generally agreed that decomposing a project into several independent subprojects can help to have a successful and effective project management. On the other hand, this may lead to inefficient use of some renewable resources and increase in the total cost and time of project. This study deals with the benefits of horizontal partnering among contractors assigned to subprojects through sharing renewable resources and proposes a model based on cooperative game theory for the problem. The improvement of the Net Present Value (NPV) of the project was considered as the benefit of cooperation among contractors. Therefore, a Mixed-Integer Non-Linear Programming (MINLP) model was developed for the resource constrained project scheduling with the objective function of maximizing the NPV of each coalition. Seven widely used cooperative game theory solution methods were used to solve the NPV allocation problem and then, stability criteria were utilized to find the best allocation scheme. An example is presented in the paper to more comprehensively illustrate the problem.
\end{abstract}

(C) 2020 Sharif University of Technology. All rights reserved.

\section{Introduction}

Many stakeholders are involved in the implementation of construction projects and it is generally accepted that there is a strong link between project success and effective relationship between stakeholders [1]. The benefits of this relationship or collaboration will ultimately lead to greater satisfaction of the stakeholders. Contractors at different levels of a construction project are among these stakeholders. They carry out a large portion of the work done in a project and may account for up to $90 \%$ of its total value [2-4].

In recent years, cooperation between project stakeholders, including the main contractors and subcontractors, has been considered by various researchers [5-7]. Phua and Rowlinson [8] perceived

\footnotetext{
*. Tel.: +982142863000

E-mail address: m_akhbari@iauec.ac.ir
}

cooperation as a vital element of construction project success. Chan et al. [9] evaluated the critical success factors such as efficient cooperation, effective communication, and mutual trust between contracting parties for running partnering construction projects. Hartmann et al. [4], who dealt with the subcontractor selection process for the main contractors in Singapore, considered cooperation as one of the important selection criteria.

One of the problems that occur in cooperation is how the benefits are divided among the parties. Thus, the use of game theory in such situations that there is a conflict between rational parties is an efficient approach. In fact, using game theory, a win-win solution can be found for all parties or players.

A limited number of studies have been conducted about the application of game theory to the problem of interaction between project stakeholders. Perng et al. [10] studied the formwork subcontractors cooperation by hiring open shop workers in a coalition, rather than union workers, to earn more profit. They used 
Shapley value and nucleolus to divide profit among subcontractors.

Asgari and Afshar [11] used a cooperative game theory approach to modeling of subcontractors cooperation in time. They considered real cost of the project based on time-cost and time-efficiency functions and showed that cooperation of subcontractors could improve total real cost. Finally, the benefits of coalition were distributed using the Shapely value and nucleolus methods. Barough et al. [12] applied prisoner dilemma and chicken game to solving the construction project conflicts between the involved parties. Tsai and chi [13] showed the importance of cooperative learning for achieving win-win outcomes between two parties.

Joint resource management is one of the areas of cooperation among subcontractors in the construction projects. Asgari et al. [14] suggested cooperative game theory as an efficient tool for analyzing joint resource management in construction projects. In their study, first, characteristic functions of subcontractors for all possible coalitions were determined using a resourceleveling model. Then, cooperation benefits were allocated to the subcontractors using various cooperative game theoretic solution methods. Finally, plurality rule and propensity to disrupt methods were used to select the most acceptable and stable allocation.

Samsami and Tavakolan [15] divided partnership of subcontractors into two directions, namely horizontal and vertical. They defined a model to build and analyze joint resource management as a horizontal partnership based on game theory. The objective function of their model was to minimize the net cost consisting of the cost of hiring a fixed number of resources during the project and the cost of repair/maintenance. They showed the overall payoff of increase in coalition and used Shapely value method to allocate benefits of joint resource management.

Previous research has shown that one of the main restrictions on construction projects affecting project cost and time is limited renewable resources, such as labor and equipment [16-17]. So far, two different types of resource-restricted problems have been considered: resource-smoothing (also known as resource leveling) problems and resource-constrained (also known as resource allocation) problems. The project resource leveling problem has been proposed to smooth resource usage and reduce resource fluctuation with determined project finish time, while ResourceConstrained Project Scheduling Problem (RCPSP) focuses on optimizing project duration with limited resources. In this study, the latter is considered and resource-constrained scheduling is carried out with the objective function of maximizing Net Present Value (NPV) of the project.

The rest of this paper is organized as follows. Section 2 defines the problem in two sub-sections of which the first formulates the effect of cooperation among contractors and the second reviews the mechanisms for allocation of cooperative gains and the stability criteria of different allocation schemes. Section 3 is devoted to solving an example and analysis of the results. Finally, the conclusions are presented in Section 4.

\section{Problem definition}

This study investigates the benefits of cooperation among contractors assigned to subprojects through sharing renewable resources. Improvement in the NPV of the project is considered as the benefit of cooperation and the problem is determining the share of each contractor from this improvement. To solve the problem, first, a coalition-based multi-mode RCPSP with the objective function of finding the best NPV for each coalition among contractors is developed and then, various solutions of cooperative games with Transferable Utility (TU-cooperative games) are used for the distribution of the NPV among contractors in the grand coalition.

\subsection{RCPSP of maximizing the NPV}

Over the past decades, RCPSP has been extensively addressed in numerous studies [18-21]. Whereas the RCPSP attempts to minimize the total project duration or makespan, several alternative objectives exist, such as minimization of the resource idle time, minimization of earliness and tardiness, or maximization of project NPV [22].

Yang et al. [23] presented an integer programming algorithm for solving the limited-resource project scheduling problem with the objective of maximizing project NPV. Vanhoucke et al. [24] studied RCPSP with discounted cash flows. They assumed that each activity of the RCPSP had certain resource requirements and a known deterministic cash flow. They developed a depth-first branch-and-bound algorithm, which used a new fast recursive search algorithm for the max-npv problem. Vanhoucke [25] developed a scatter search procedure for maximizing the NPV of a resource-constrained project with fixed activity cash flow. Khoshjahan et al. [26] considered the RCPSP with the objective of minimizing the NPV of the earliness-tardiness penalty costs. They first modeled the problem and then, proposed two meta-heuristics, namely genetic algorithm and simulated annealing, to solve it. Leyman and Vanhoucke [27] discussed the single- and multi-mode Resource-Constrained Project Scheduling Problems with Discounted Cash flows (RCPSPDC and MRCPSPDC) and solved the model with a proposed genetic algorithm metaheuristic.

In this study, maximizing the NPV is taken into account as the objective function of the scheduling problem to achieve an assignment of modes to activities 
as well as precedence and resource-feasible starting times for all activities. In other words, this study mathematically formulates the model for a Multimode Resource Constrained Project Scheduling Problem with Discounted Cash flows (MRCPSPDC). In this problem, it is assumed that:

- Each activity can be performed in several modes and in each mode, it has a specific duration, cash flow (positive or negative), and amount of renewable resources;

- Cash flows are assumed to occur upon activity finish time;

- The project is decomposed into several subprojects with due dates under bonus-penalty policies. Each subproject assigned to a contractor is aimed at maximizing their own NPV;

- Bonus (penalty) is allotted when the subproject is finished before (after) its pre-defined due date;

- Contractors can form a coalition and the scheduling problem of all subprojects performed in the coalition is an MRCPSPDC model.

The MRCPSPDC model of coalition $S \in 2^{N} \backslash \phi$ is developed as follows.

The notations used in the model are summarized in Table 1. Using the notations, the proposed mathematical model is formulated as:

Table 1. Summary of notations

\begin{tabular}{|c|c|}
\hline \multicolumn{2}{|l|}{ Indices: } \\
\hline$i, j$ & Activity \\
\hline$t, b$ & Time interval \\
\hline$p$ & Resource \\
\hline$l \in\left\{1,2, \ldots, L_{i}\right\}$ & Mode \\
\hline$s \in\left\{1,2, \ldots, 2^{n}-1\right\}$ & Coalition \\
\hline$k$ & Contractor or sub-project \\
\hline \multicolumn{2}{|l|}{ Sets: } \\
\hline I & Set of all activities $s \in\{0,1, \ldots, m\}$ \\
\hline$R$ & Set of renewable resources $=\{1,2, \ldots, P\}$ \\
\hline$E$ & Set of all intervals $=\{1, \ldots, T\}$ \\
\hline$N$ & Grand coalition that includes all contractors $=\{1,2, \ldots, n\}$ \\
\hline$M_{i}$ & Set of all modes of activity $i=\left\{1, \ldots, L_{i}\right\}$ \\
\hline Act $_{s}$ & Set of activities performed by coalition $s=\left\{i \mid A_{i k}=1, k \in C_{s}\right\}$ \\
\hline$C_{s}$ & $s$-th coalition of contractors ( $s$-th subset of grand coalition $N$ ) \\
\hline \multicolumn{2}{|l|}{ Parameters: } \\
\hline$m$ & Number of activities \\
\hline$L_{i}$ & Number of modes of activity $i$ \\
\hline$T$ & Time horizon of the project \\
\hline$n$ & Number of contractors \\
\hline$A_{i k}=\left\{\begin{array}{l}1 \\
0\end{array}\right.$ & $\begin{array}{l}\text { If activity } i \text { is performed by contractor } k \\
\text { otherwise }\end{array}$ \\
\hline$P$ & Number of renewable resources \\
\hline$d_{i l}$ & Duration of activity $i$ executed in mode $l$ \\
\hline pred $_{i j}=\left\{\begin{array}{l}1 \\
0\end{array}\right.$ & $\begin{array}{l}\text { If activity } i \text { is the predecessor of activity } j \\
\text { otherwise }\end{array}$ \\
\hline respkt & Number of units of renewable resource $p$ available to contractor $k$ in time $t$ \\
\hline$r_{p i l}$ & Number of units of renewable resource $p$ required by activity $i$ executed in mode $l$ \\
\hline$c f_{i l}$ & Net cash flow associated with activity $i$ in mode $l$ \\
\hline$w_{k}$ & Penalty per time unit of delay of sub-project $k$ \\
\hline$\vartheta_{k}$ & Bonus per time unit for early completion of sub-project $k$ \\
\hline$c d_{k}$ & Due date of sub-project $k$ \\
\hline$\alpha$ & Discount rate \\
\hline \multicolumn{2}{|l|}{ Binary variables: } \\
\hline$x_{i l t}=\left\{\begin{array}{l}1 \\
0\end{array}\right.$ & $\begin{array}{l}\text { If activity } i \text { is performed in mode } l \text { and finished at time } t, \forall i \in I, \forall l \in M_{i} \text {, and } \forall t \in E \\
\text { otherwise }\end{array}$ \\
\hline$y_{k}=\left\{\begin{array}{l}1 \\
0\end{array}\right.$ & $\begin{array}{l}\text { If sub-project } k \text { is finished after its due date }\left(c d_{k}\right) \\
\text { otherwise }\end{array}$ \\
\hline \multicolumn{2}{|c|}{ Continuous variables: } \\
\hline$F T_{k}$ & Makespan or finish time of sub-project $k, \forall k \in N$ \\
\hline$N P V_{s}$ & $N P V$ of coalition $s, \forall s \subset N$ \\
\hline
\end{tabular}


MRCPSPDC model:

$$
\begin{aligned}
\max N P V_{s}= & \sum_{k \in C_{s}}\left[\sum_{i \in A c t_{s}} \sum_{l=1}^{L_{i}} \sum_{t=1}^{T} c f_{i l} x_{i l t} e^{-\alpha t}\right. \\
& -w_{k}\left(F T_{k}-c d_{k}\right) y_{k} e^{-\alpha F T_{k}} \\
& \left.+\vartheta_{k}\left(c d_{k}-F T_{k}\right)\left(1-y_{k}\right) e^{-\alpha F T_{k}}\right]
\end{aligned}
$$

subject to,

$$
\begin{aligned}
& \sum_{l=1}^{L_{i}} \sum_{t=1}^{T} x_{i l t}=1 \quad \forall i \in A c t_{s}, \\
& \operatorname{pred}_{i j} \sum_{l=1}^{L_{i}} \sum_{t=1}^{T} t x_{i l t} \leq \sum_{l=1}^{L_{j}} \sum_{t=1}^{T}\left(t-d_{j l}\right) x_{j l t} \\
& \forall i, j \in A c t_{s}, \\
& \sum_{l=1}^{L_{i}} \sum_{t=1}^{T} t x_{i l t} A_{i k} \leq F T_{k} \quad \forall k \in C_{s}, \quad \forall i \in A c t_{s}, \\
& \sum_{i \in A c t_{s}} \sum_{l=1}^{L_{i}} r_{p i l} \quad \sum_{b=t}^{t+d_{i l}-1} x_{i l t} \leq \sum_{k=1}^{N} r e s_{p k t} \\
& \forall t \in E, \quad \forall p \in R, \\
& F T_{k}\left(1-y_{k}\right) \leq c d_{k} \quad \forall k \in C_{s}, \\
& c d_{k} y_{k} \leq F T_{k} \quad \forall k \in C_{s}, \\
& F T_{k} \geq 0 \quad \forall k \in C_{s}, \\
& x_{i l t}\{0,1\} \quad \forall i \in A c t_{s}, \quad \forall t \in E, \quad \forall k \in C_{s} . \\
& y_{k} \in\{0,1\} \quad \forall M_{i},
\end{aligned}
$$

Objective function (1) maximizes the NPV of the $s$-th coalition based on a discount rate $\alpha$. It consists of three parts:

(a) The present values of cash flow for all the activities performed by coalition $s$;

(b) The present values of tardiness penalties for all contractors included in coalition $s$;

(c) The present values of earliness bonuses for all contractors included in coalition $s$.

Eq. (2) states that every activity is assigned exactly one mode and exactly one finishing time. Constraint (3) ensures the precedence relations between activities. Inequality (4) ensures that the makespan of subproject $k, F T_{k}$, is the maximum finish time of all of its activities. Constraint (5) enforces the resource constraints at time interval $t$. Inequalities (6) and (7) determine the earliness and tardiness of sub-project $k$, respectively. Finally, Constraints (8)-(10) denote the domain of the variables.

Based on above model, cooperation among contractors via joint resource management can increase their gain (NPV) by using the renewable resources efficiently. A TU-cooperative game $(N, \nu)$ with the set of players $N$ including all contractors and the characteristic function $\nu$ equal to NPV can be used to determine the share of each contractor in the grand coalition.

\subsection{Cooperative game theory}

Game theory is "the study of mathematical models of conflict and cooperation between intelligent rational decision-makers" [28,29] and is divided into two branches: cooperative and non-cooperative. A game is cooperative (or coalitional) if the players are able to form binding commitments (or coalitions) externally enforced. A game is non-cooperative if players cannot form alliances or if all agreements need to be selfenforcing [29].

One of the problems in cooperative game theory is how to distribute the payoff of coalition among the members or players [28].

Cooperative games can be Transferable-Utility (TU) games or Non-Transferable-Utility (NTU) games. TU-cooperative games are used to model situations in which the players in a coalition can compare and transfer part of their utilities with each other. In the situations of NTU-cooperative games, it is not always possible for the players to compare or transfer utilities.

The rest of this section introduces the basic notation, definitions, and notions of the TU-cooperative game theory.

\subsubsection{Basic definitions and concepts}

Definition 1. A TU-game is an ordered pair $(N, \nu)$ consisting of the player set $N$ (with $n$ players) and the characteristic function $\nu: 2^{N} \rightarrow R$ with $\nu(\phi)=0$. For each coalition $S \subseteq N$, The real number $\nu(S)$ denotes the maximal worth the members in $S$ can obtain or the cost savings they can make if they cooperate [30,31].

Definition 2. Let $x \in R^{n}$ be a payoff vector, where $x_{i}$ represents the value allocated to player $i \in N$ in the grand coalition. A payoff vector $x \in R^{n}$ is called an imputation for the game $(N, \nu)$ if it satisfies efficiency an individual rationality conditions, i.e.:

(i) $\sum_{i \in N} x_{i}=\nu(N)$,

(ii) $x_{i} \geq \nu(i)$. 
The set of imputations of the game $(N, \nu)$ is denoted by $I(\nu)[31]$.

Definition 3. The core $C(\nu)$ of the game $(N, \nu)$ is the set:

$$
C(\nu)=\left\{x \in I(\nu) \mid \sum_{i \in S} x_{i} \geq \nu(S), \quad \forall S \in 2^{N} \backslash \phi\right\},
$$

or the Core of the game $(N, \nu), C(\nu)$, is a set of imputations that satisfy:

(i) $\sum_{i \in N} x_{i}=\nu(N)$,

(ii) $\sum_{i \in S} x_{i} \geq \nu(S), \quad \forall S \in 2^{N} \backslash \phi$.

If $x \in C(\nu)$, no player has an incentive for deviation to form a different coalition [31].

\subsubsection{Solution concepts for cooperative TU-games \\ Shapely value}

The solution concept of Shapely value was introduced by Shapley in 1953 [32].

Definition 4. Given a cooperative game $(N, \nu)$, the Shapley value $\phi_{i}(v)$, which is the expected payoff of player $i \in N$, is defined by:

$$
\left.\phi_{i}(v)=\sum_{S: i \notin S} \frac{|S| !(n-1-|S|) !}{n !} \nu(S \cup\{i\})-\nu(S)\right) .
$$

$$
\tau \text {-value }
$$

Tijs defined the solution concept of $\tau$-value for each quasi-balanced game in 1981 [33].

Definition 5. For a quasi-balanced game $(N, \nu)$, the $\tau$-value $\tau(\nu)$ is defined by:

$$
\tau(v):=\alpha m(N, v)+(1-\alpha) M(N, v)
$$

where $m(N, \nu)$ and $M(N, \nu)$ are the lower vector and upper vector of the game $(N, \nu)$, respectively, and $\alpha \in$ $[0,1]$ is uniquely obtained from $[31,33]$ :

$$
\sum_{i \in N} \tau_{i}(v)=\nu(N)
$$

\section{Average lexicographic value}

The Average Lexicographic value or $A L$-value is defined for balanced cooperative games, which are games with a non-empty core $[31,34]$.

Given a balanced game $(N, \nu)$ and an ordering $\sigma$ of the players in $N$, the lexicographic maximum of the core $C(\nu)$ of $\nu$ with respect to is denoted by $L^{\sigma}(v)$. It is the unique point in $C(\nu)$ with the following properties:

$$
\begin{aligned}
& \left(L^{\sigma}(v)\right)_{\sigma(1)}=\max \left\{x_{\sigma(1)} \mid x \in C(\nu)\right\} \\
& \left(L^{\sigma}(v)\right)_{\sigma(2)}=\max \left\{x_{\sigma(2)} \mid x \in C(\nu)\right. \text { with } \\
& \left.x_{\sigma(1)}=\left(L^{\sigma}(v)\right)_{\sigma(1)}\right\}, \\
& \ldots \\
& \left(L^{\sigma}(v)\right)_{\sigma(n)}=\max \left\{x_{\sigma(n)} \mid x \in C(\nu)\right. \\
& \qquad \text { with } x_{\sigma(i)}=\left(L^{\sigma}(v)\right)_{\sigma(i)}, \\
& i=1,2, \ldots, n-1\} .
\end{aligned}
$$

Note that $L^{\sigma}(v)$ is an extreme point of $C(\nu)$ for each $\sigma \in \pi(N)$.

Definition 6. For a balanced game $(N, \nu)$, the average lexicographic value $A L(v)$ is defined by the average of all the lexicographically maximal vectors of the core $C(\nu)$, i.e.:

$$
A L(v)=\frac{1}{n !} \sum_{\sigma \in \pi(N)} L^{\sigma}(v)
$$

\section{The equal split-off set}

Equal split-off set is introduced as a solution concept for cooperative games based on egalitarian considerations [35].

Given a game $(N, \nu)$, in the first step, one of the coalitions with maximal average worth, say $T_{1}$, is formed, i.e.:

$$
T_{1} \in \arg \max _{S \in 2^{N}} \frac{v_{k}(S)}{|S|},
$$

and the worth of $\nu\left(T_{1}\right)$ is equally divided among the players in $T_{1}$.

In step 2, one of the coalitions in $N \backslash T_{1}$ with maximal average marginal, say $T_{2}$, is formed, and the value $v\left(T_{1} \cup T_{2}\right)-v\left(T_{1}\right)$ is equally divided among the players in $T_{2}$.

Similarly, in step $k, T_{k}$ is formed, i.e.:

$$
T_{k} \in \arg \max _{S \in 2} \frac{v\left(\bigcup_{i=1}^{N \backslash \sum_{i=1}^{k-1} T_{i}} T_{i} \cup s\right)-v\left(\bigcup_{i=1}^{k-1} T_{i}\right)}{|S|}
$$

and the value of $v\left(\bigcup_{i=1}^{k-1} T_{i} \bigcup s\right)-v\left(\bigcup_{i=1}^{k-1} T_{i}\right)$ is equally divided among the players in $T_{k}$. This process continues until a partition of $N$ of the form $\left\langle T_{1}, \ldots, T_{k}\right\rangle$ for some $1 \leq k \leq n$ is reached [31].

\section{Nucleolus}

The nucleolus was first introduced by Schmeidler (1969) as a solution concept in cooperative game theory [36]. 
Consider a game $(N, \nu)$ and a payoff vector $x \in$ $R^{n}$. The excess of the coalition $S \in 2^{N} \backslash \phi$ associated with $x$ is defined as $e(S, x)=v(S)-\sum_{i \in S} x_{i}$, which is the gain that players in coalition $S$ can obtain if they withdraw the grand coalition $N$ under payoff $x$ and instead, take the payoff $v(S)$. In other words, $e(S, x)$ represents a measure of dissatisfaction of coalition $S$ in the grand coalition.

The nucleolus tries to find an imputation inside the core, $x \in C(\nu)$, that lexicographically minimizes the vector of non-increasing ordered excesses of coalitions $e(S, x), S \in 2^{N} \backslash \phi$. The nucleolus of the game $(N, \nu)$ can be reached by solving a sequence of Linear Programs (LPs) defined recursively as follows:

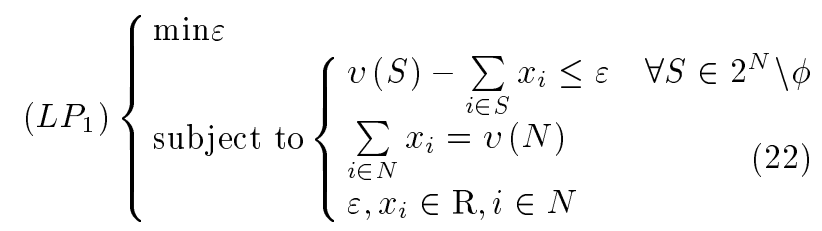

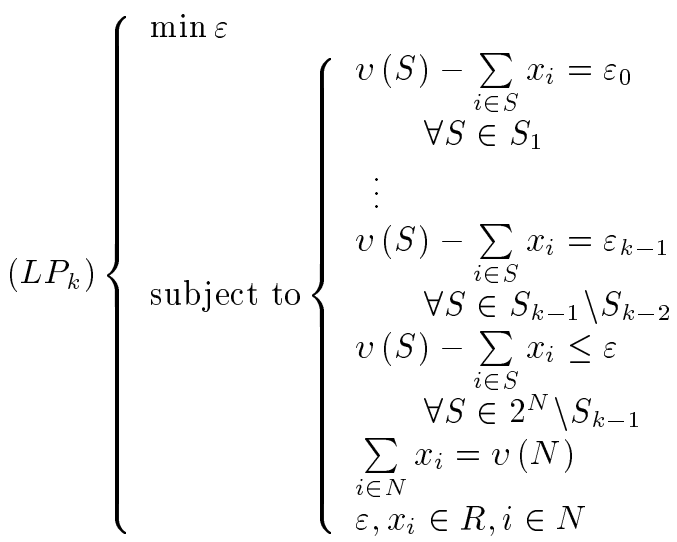

where $\varepsilon_{k-1}$ is the optimal objective value for $L P_{k-1}$ and $S_{k-1}$ is the set of coalitions for which the excess has been fixed in a previous LP in the sequence [3740]. Fromen [41] introduced an algorithm for solving this sequence of LPs.

\section{Per-capita excess}

The per-capita nucleolus represents a measure of dissatisfaction per capita of a coalition. It is determined by replacing:

$$
e(S, x)=v(S)-\sum_{i \in S} x_{i}
$$

with:

$$
\bar{e}(S, x)=\frac{v(S)-\sum_{i \in S} x_{i}}{|S|},
$$

in the optimization programs of the nucleolus [30].

\section{Nash-Harsanyi ( $\mathrm{N}-\mathrm{H})$ solution}

The Nash-Harsanyi (N-H) solution concept maximizes the product of the difference between the allocated utilities (income or NPV in this paper) from cooperation in grand coalition and the non-cooperation case, subject to core conditions, by equating the utility gains of all players [36,39]. Given a cooperative game $(N, \nu)$, the optimization model of the $\mathrm{N}-\mathrm{H}$ solution is as follows:

$$
\max \prod_{\forall i \in N}\left(x_{i}-v(i)\right)
$$

subject to,

$$
\begin{aligned}
& v(S)-\sum_{i \in S} x_{i} \leq 0 \quad \forall S \in 2^{N} \backslash \phi, \\
& \sum_{i \in N} x_{i}=v(N), \\
& x_{i} \in R, i \in N .
\end{aligned}
$$

\subsubsection{Solution stability criteria}

Based on the mathematical calculations of the core, all the solutions in it are potentially acceptable for all players in the grand coalition. However, in practice, many of these allocations may seem unfair from the viewpoint of some of the players and they have incentive for leaving the grand coalition and forming partial coalitions or act individually. This makes grand coalition unstable. Therefore, for the sake of stability, the concept of "fairness" in allocation should be considered.

On the other hand, players, knowing that they can gain more in the core, may bargain or threaten the grand coalition to leave. Thus, an additional concept of stability, namely "propensity to disrupt," should be considered.

\section{Fairness index}

The Shapley-Shubik power index was suggested by Shapley and Shubik [42] to measure power in voting game. Loehman et al. [43] used an index similar to the Shapley-Shubik power index to measure power in a cooperative game. This index was used in several later studies to evaluate the fairness of a given allocation among all players $[37,40,44]$.

The power index $\left(\alpha_{i}\right)$ compares the gain of player $i \in N$ with the gains of coalition. The power index $\left(\alpha_{i}\right)$ is:

$$
\alpha_{i}=\frac{x_{i}-v(i)}{\sum_{i \in N}\left(x_{i}-v(i)\right)}, \quad i \in N ; \quad \sum_{i \in N} \alpha_{i}=1,
$$

where $x_{i}$ is the solution allocation for player $i \in N$ and $\nu(i)$ is the worth of player $i$.

The power index of each player is calculated separately. If power is distributed almost evenly among the players, then the coalition is more likely to be stable. Based on the concept of power index, the Fairness Index (FI) can be defined as:

$$
\mathrm{FI}=\frac{\sigma_{\alpha}}{\bar{\alpha}}, \quad 0 \leq \mathrm{FI} \leq 1,
$$


where FI indicates the Fairness Index. $\sigma_{\alpha}$ is the standard deviation and $\bar{\alpha}$ represents the average value. The greater the value of FI, the larger the instability of the solution $[37,40,44]$.

\section{Propensity to Disrupt (DP)}

Propensity to Disrupt ( $D P$ ), as another measure of solution stability, was introduced by Gately in 1974 [45]. $D P_{i}$ is defined as the ratio of how much the other players would lose if player $i \in N$ does not cooperate in the grand coalition to how much the player would lose in this situation, i.e.:

$$
D P_{i}=\frac{\sum_{j \in N \backslash\{i\}} x_{j}-v(N \backslash\{i\})}{x_{i}-v(i)}, \quad i \in N
$$

where $x_{i}$ is the solution allocation for player $i \in N$; $v(N \backslash\{i\})$ is the worth of coalition $N \backslash\{i\}$; and $v(i)$ is the worth of player $i$. $D P$ can be defined for the solution as:

$$
D P=\max _{i \in N}\left(D P_{i}\right)
$$

The greater the value of $D P$, the larger the instability of the solution. Decision makers must determine an acceptance upper limit for DP and eliminate any imputation not inside the limit $[37,45]$.

\section{Case study}

\subsection{Description}

The proposed approach is illustrated with an example. Consider a construction project including three similar sub-projects with three contractors in charge. The due date of all sub-projects is at the end of time unit 25 with delay penalty and earliness bonus of 30 and $20 \$$ per time unit, respectively. The discount rate is assumed $2 \%$. Each activity has two possible execution modes. Table 2 presents the list of activities, corresponding precedence relations between them and their durations, required resources, and cash flow with respect to each mode.

Number of units of each renewable resource available to each contractor at different time intervals is shown in Figure 1 and 2.

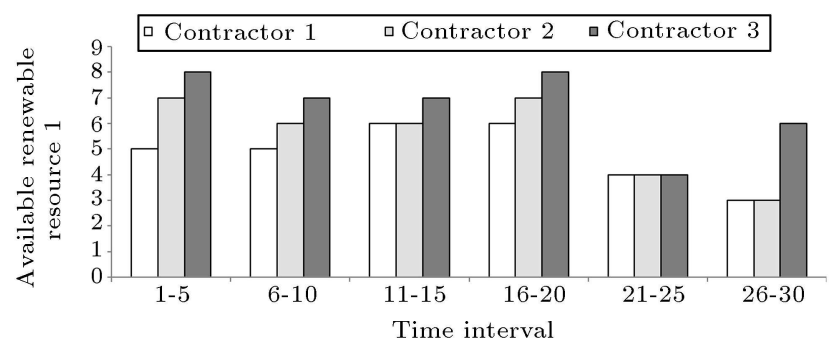

Figure 1. Number of units of renewable resource 1 available to each contractor at each time interval.

Table 2. The list of activities, corresponding precedence relations between them and their durations, required resources,

\begin{tabular}{|c|c|c|c|c|c|c|c|c|c|c|}
\hline \multirow{4}{*}{ Subcontractor } & \multirow{4}{*}{ Activity } & \multirow{4}{*}{ Precedence } & \multicolumn{8}{|c|}{ Mode } \\
\hline & & & \multicolumn{4}{|c|}{1} & \multicolumn{4}{|c|}{2} \\
\hline & & & \multirow[t]{2}{*}{ Duration } & \multicolumn{2}{|c|}{$\begin{array}{c}\text { Required } \\
\text { resource }\end{array}$} & \multirow[t]{2}{*}{ Cash flow } & \multirow[t]{2}{*}{ Duration } & \multicolumn{2}{|c|}{$\begin{array}{c}\text { Required } \\
\text { resource }\end{array}$} & \multirow[t]{2}{*}{ Cash flow } \\
\hline & & & & 1 & 2 & & & 1 & 2 & \\
\hline \multirow{6}{*}{1} & 1 & - & 5 & 1 & 3 & -320 & 3 & 2 & 4 & -306 \\
\hline & 2 & 1 & 4 & 2 & 4 & -508 & 3 & 4 & 6 & -564 \\
\hline & 3 & 1 & 10 & 0 & 1 & -330 & 6 & 0 & 0 & -346 \\
\hline & 4 & 2,3 & 6 & 3 & 0 & -280 & 4 & 5 & 3 & -300 \\
\hline & 5 & 3 & 10 & 5 & 2 & -780 & 8 & 6 & 5 & -792 \\
\hline & 6 & 4,5 & 6 & 1 & 3 & 4596 & 4 & 2 & 4 & 4550 \\
\hline \multirow{6}{*}{2} & 7 & - & 5 & 1 & 3 & -320 & 3 & 2 & 4 & -306 \\
\hline & 8 & 7 & 4 & 2 & 4 & -508 & 3 & 4 & 6 & -564 \\
\hline & 9 & 7 & 10 & 0 & 1 & -330 & 6 & 0 & 0 & -346 \\
\hline & 10 & 8,9 & 6 & 3 & 0 & -280 & 4 & 5 & 3 & -300 \\
\hline & 11 & 9 & 10 & 5 & 2 & -780 & 8 & 6 & 5 & -792 \\
\hline & 12 & 10,11 & 6 & 1 & 3 & 4596 & 4 & 2 & 4 & 4550 \\
\hline \multirow{6}{*}{3} & 13 & - & 5 & 1 & 3 & -320 & 3 & 2 & 4 & -306 \\
\hline & 14 & 13 & 4 & 2 & 4 & -508 & 3 & 4 & 6 & -564 \\
\hline & 15 & 13 & 10 & 0 & 1 & -330 & 6 & 0 & 0 & -346 \\
\hline & 16 & 14,15 & 6 & 3 & 0 & -280 & 4 & 5 & 3 & -300 \\
\hline & 17 & 15 & 10 & 5 & 2 & -780 & 8 & 6 & 5 & -792 \\
\hline & 18 & 16,17 & 6 & 1 & 3 & 4596 & 4 & 2 & 4 & 4550 \\
\hline
\end{tabular}
and cash flows with respect to each mode. 


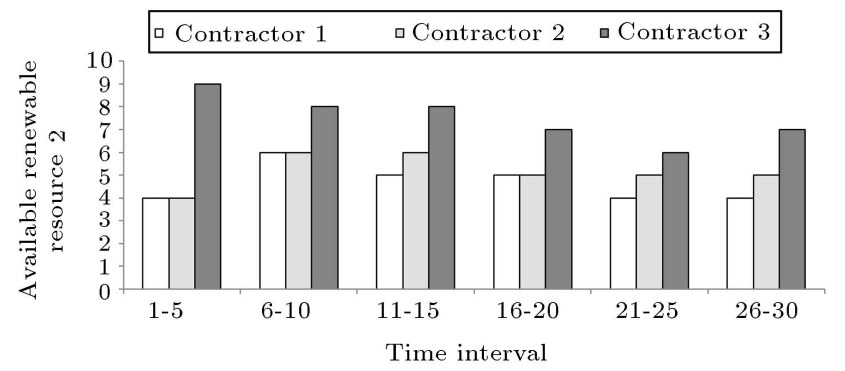

Figure 2. Number of units of renewable resource 2 available to each contractor at each time interval.

\subsection{NPVs for various degrees of cooperation}

Based on the above information, the proposed mathematical models of all possible coalitions including non-cooperation (act alone), partial cooperation (subset coalition), and the grand coalition are solved by branch-and-reduce optimization navigator (BARON) under GAMS. The results consist of the best NPV found for each coalition, the finish time of each activity, and the makespan of each sub-project (Table 3 ).

As shown in Table 3, if no coalition is created or the contractors perform the subprojects separately, the NPV of the project will be $3266.41 \$$; if the subset coalitions of $(1,2),(1,3)$, and $(2,3)$ are formed, the NPV of the project will be $3423.014 \$, 3381.122 \$$, and
$3400.969 \$$, respectively; and if the project is performed by grand coalition, the NPV will be $3553.879 \$$.

The resulting Gantt charts for all 5 possible combinations of coalitions are shown in Figure 3. In this figure, the color of the bars for all activities of one coalition is the same.

\subsection{The core of the cooperation game}

The allocation of the NPV to all the three contractors cannot migrate outside the core, $x \in C(\nu)$. The core of the game $C(\nu)$ is shown in Figure 4, representing all possible payoff allocations.

\subsection{NPV allocation schemes based on the solutions}

By applying the introduced 7 methods of cooperative game theory to the case study, the NPV assignment strategy for each method is deduced and summarized in Table 4. Apparently, the sum of the allocated values for each contractor is equal to the total NPV $(3553.879 \$)$ through grand coalition. Meanwhile, all of the allocation schemes satisfy the core requirements as shown in Table 4.

\subsection{Stability for different allocation schemes}

In the following, in order to investigate the stability of different allocation schemes presented in Section 2.2.3,

Table 3. Net Present Value (NPV) and makespan of each sub-project for various degrees of cooperation.

\begin{tabular}{|c|c|c|c|c|c|c|c|}
\hline \multirow[b]{2}{*}{ Scenario } & \multirow[b]{2}{*}{ Coalition } & \multirow{2}{*}{$\begin{array}{l}\text { NPV }(\$) \text { of } \\
\text { coalition }\end{array}$} & \multirow[b]{2}{*}{ Combinations } & \multirow{2}{*}{$\begin{array}{c}\text { NPV }(\$) \text { of } \\
\text { project }\end{array}$} & \multicolumn{3}{|c|}{ Makespan } \\
\hline & & & & & $\begin{array}{c}\text { Sub-project } \\
1 \\
\end{array}$ & $\begin{array}{c}\text { Sub-project } \\
2 \\
\end{array}$ & $\begin{array}{c}\text { Sub-project } \\
\mathbf{3} \\
\end{array}$ \\
\hline \multirow{3}{*}{$\begin{array}{l}\text { Act } \\
\text { alone }\end{array}$} & 1 & 1064.13 & \multirow{3}{*}{$(1),(2),(3)$} & \multirow{3}{*}{3266.41} & 24 & - & - \\
\hline & 2 & 1069.923 & & & - & 24 & - \\
\hline & 3 & 1132.357 & & & - & - & 25 \\
\hline \multirow{4}{*}{$\begin{array}{l}\text { Subset } \\
\text { coalition }\end{array}$} & 1,2 & 2290.657 & $\{(1,2),(3)\}$ & 3423.014 & 21 & 26 & - \\
\hline & 1,2 & 2290.657 & $\{(1,2),(3)\}$ & 3423.014 & 21 & 26 & - \\
\hline & 1,3 & 2311.199 & $\{(1,3),(2)\}$ & 3381.122 & 27 & - & 21 \\
\hline & 2,3 & 2336.839 & $\{(1),(2,3)\}$ & 3400.969 & - & 25 & 22 \\
\hline Grand coalition & $1,2,3$ & 3553.879 & $\{(1,3,2)\}$ & 3553.879 & 28 & 21 & 21 \\
\hline
\end{tabular}

Table 4. Net Present Value (NPV) assignment using different schemes.

\begin{tabular}{lcccc}
\hline \multirow{2}{*}{$\begin{array}{c}\text { Solution } \\
\text { scheme }\end{array}$} & \multicolumn{3}{c}{ NPV allocation $(\$)$} & \multirow{2}{*}{ In core } \\
\cline { 2 - 4 } & $\boldsymbol{x}_{\mathbf{1}}$ & $\boldsymbol{x}_{\mathbf{2}}$ & $\boldsymbol{x}_{\mathbf{3}}$ & \\
\hline Shapely value & 1160.319 & 1176.036 & 1217.524 & Yes \\
$\tau$-Value & 1159.952 & 1179.562 & 1214.365 & Yes \\
Average lexicographic value & 1174.702 & 1177.999 & 1201.179 & Yes \\
Equal split-off set & 1184.626 & 1184.626 & 1184.626 & Yes \\
Nucleolus & $1,160.686$ & $1,186.326$ & $1,206.868$ & Yes \\
Per-capita excess & $1,160.686$ & $1,186.326$ & $1,206.868$ & Yes \\
N-H solution & 1159.946 & 1165.749 & 1228.184 & Yes \\
\hline
\end{tabular}




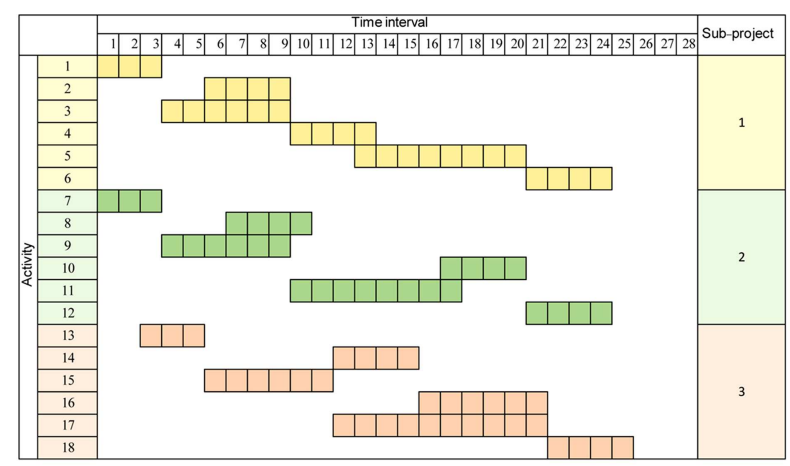

(a) The project gant chart in the non-cooperative mode (singleton coalitions) or $\{(1),(2),(3)\}$

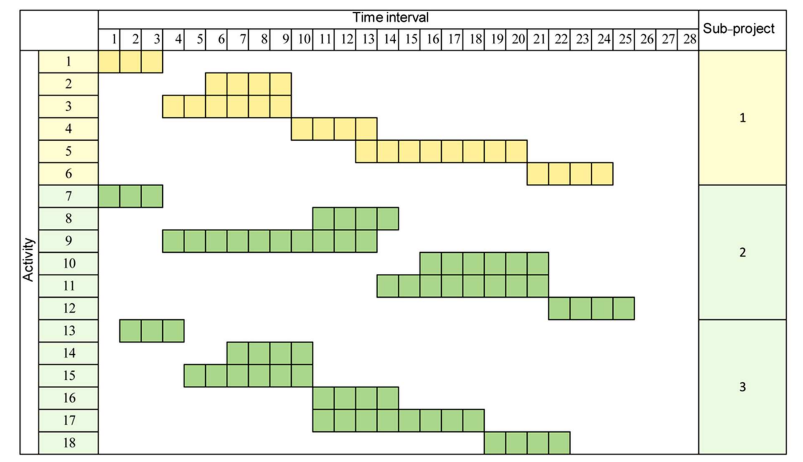

(c) The project gant chart in the situation of Contractors 2 and 3 cooperate and Contractor 1 acts alone or $\{(1),(2,3)\}$.

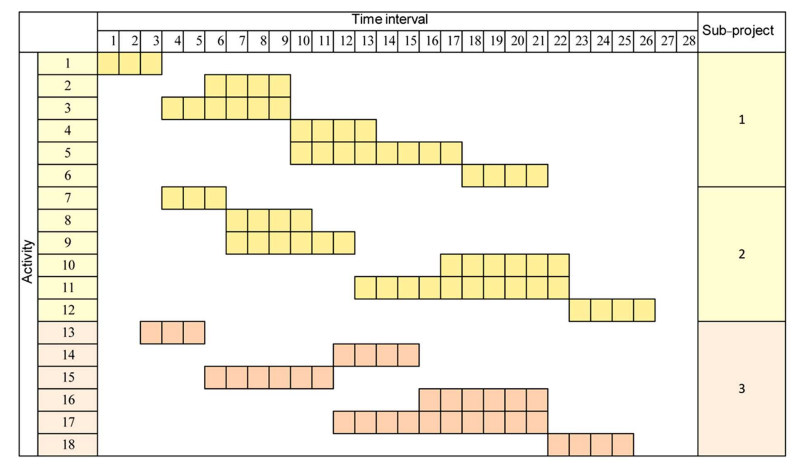

(b) The project gant chart in the situation of Contractors 1 and 2 cooperate and Contractor 3 acts alone or $\{(1,2),(3)\}$.

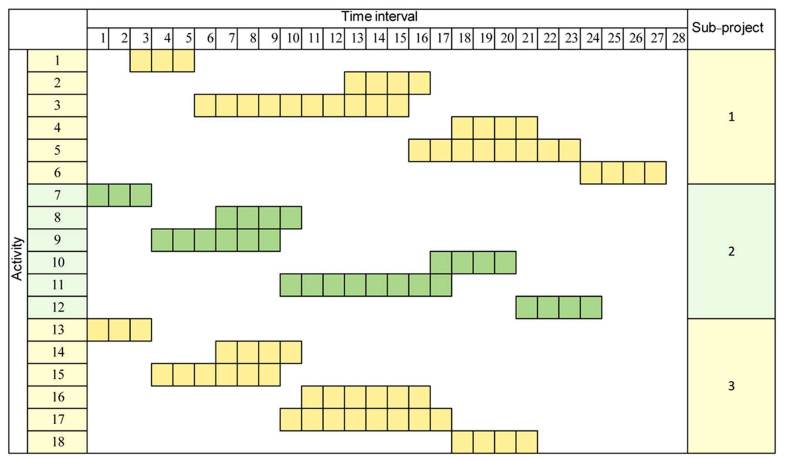

(d) The project gant chart in the situation of Contractors 1 and 3 cooperate and contractor 2 acts alone or $\{(1,3),(2)\}$.

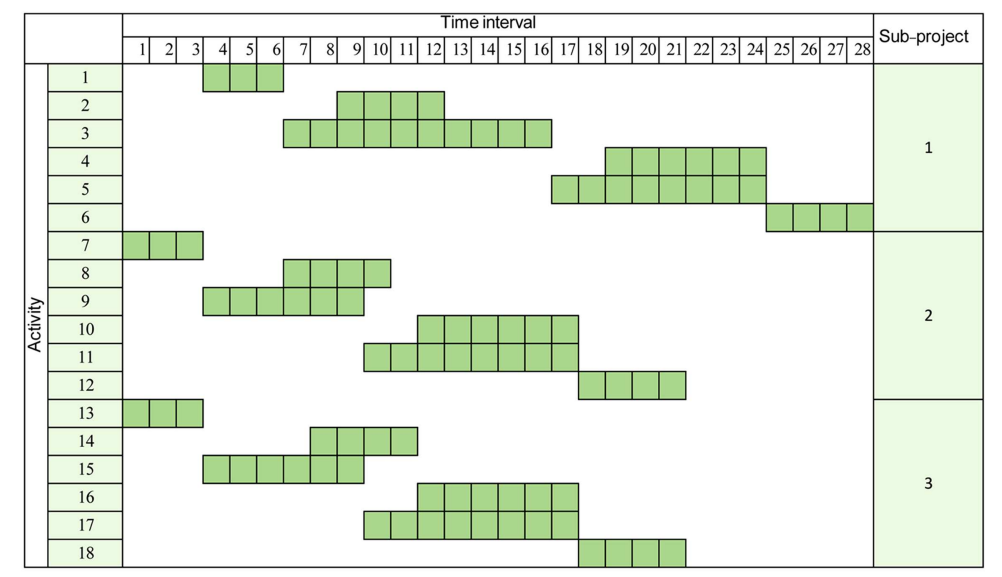

(e) The project gant chart in the situation of grand coalition or $\{(1,3),(2)\}$.

Figure 3. Gantt charts for all possible combinations of coalitions.

the values of DP and Shapley-Shubik Power Index are calculated.

Table 5 shows the $D P$ value for each contractor using the 7 allocation methods. It can be observed that the calculated $D P$ value for the third contractor employing the equal split-off set method is 1.504. According to Eq. (28) and as mentioned in Section 2.2.3, the smaller the value of $D P$, the greater the incentive of the player to join the coalition and vice versa. Therefore, one player will disrupt the coalition only when the $D P$ value is less than 1 . Therefore, the third contractor will refuse to accept the allocation strategy based on the equal split-off set method. Therefore, it can be concluded that the equal split-off set method is unstable.

Table 6 shows the power index within each scheme by utilizing Eq. (25), based on which the FI can be calculated by Eq. (26). As mentioned before, the greater the value of FI, the lower the fairness of the allocation strategy. Thus, it can be concluded that, 
Table 5. Propensity to disrupt $(D P)$ of different schemes.

\begin{tabular}{lcccc}
\hline \multirow{2}{*}{ Solution scheme } & \multicolumn{2}{c}{ NPV allocation $(\$)$} & \\
\cline { 2 - 4 } & $\boldsymbol{D P}_{\mathbf{1}}$ & $\boldsymbol{D P}_{\mathbf{2}}$ & $\boldsymbol{D P}_{\mathbf{3}}$ & $\boldsymbol{D P}$ \\
\hline Shapely value & 0.590 & 0.628 & 0.537 & 0.628 \\
$\tau$-value & 0.596 & 0.576 & 0.596 & 0.596 \\
Average lexicographic value & 0.383 & 0.598 & 0.902 & 0.902 \\
Equal split-off set & 0.269 & 0.506 & 1.504 & 1.504 \\
Nucleolus & 0.584 & 0.484 & 0.756 & 0.756 \\
Per-capita excess & 0.584 & 0.484 & 0.756 & 0.756 \\
N-H solution & 0.596 & 0.803 & 0.366 & 0.803 \\
\hline
\end{tabular}

Table 6. Fairness evaluation of each scheme.

\begin{tabular}{|c|c|c|c|c|}
\hline \multirow[t]{2}{*}{ Solution scheme } & \multicolumn{3}{|c|}{$\begin{array}{c}\text { The Shapley-Shubik } \\
\text { power index }\end{array}$} & \multirow{2}{*}{$\begin{array}{l}\text { Fairness index } \\
\qquad\left(F I_{\alpha}\right)\end{array}$} \\
\hline & $\alpha_{1}$ & $\alpha_{2}$ & $\alpha_{3}$ & \\
\hline Shapely value & 0.321 & 0.377 & 0.302 & 0.095 \\
\hline$\tau$-value & 0.333 & 0.381 & 0.285 & 0.118 \\
\hline Average lexicographic value & 0.385 & 0.376 & 0.239 & 0.200 \\
\hline Nucleolus & 0.336 & 0.405 & 0.259 & 0.179 \\
\hline Per-capita excess & 0.336 & 0.405 & 0.259 & 0.179 \\
\hline $\mathrm{N}-\mathrm{H}$ solution & 0.333 & 0.333 & 0.333 & 0.000 \\
\hline
\end{tabular}

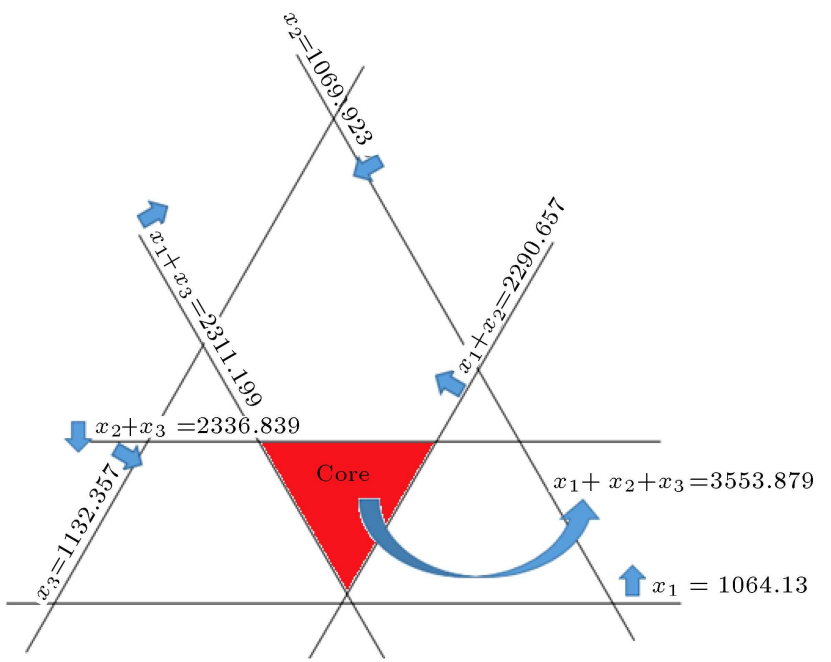

Figure 4. The core space of the game representing all possible payoff allocations.

although all of the values are within a reasonable range $\left(0 \leq \mathrm{FI}_{\alpha} \leq 1\right)$, based on Eq. (26), the scheme with the highest fairness is the $\mathrm{N}-\mathrm{H}$ solution with the lowest FI.

Therefore, in summary, the best allocation scheme can be deduced by the N-H solution method, which can meet both of the stability criteria, simultaneously.

With the N-H solution method, the utilities or NPVs $1159.946 \$, 1165.749 \$$, and $1228.184 \$$ are allocated to contractors 1, 2, and 3, respectively. Accordingly, the share of contractors 1, 2, and 3 in the grand coalition is $32.6 \%, 32.8 \%$, and $34.6 \%$, respectively.

\section{Conclusions}

One of the constraints on construction projects, which leads to increase in time and cost, is the limitation of renewable resources (e.g., labor or equipment). Sharing this resources is one of the areas of cooperation among the contractors of the project, which can lead to decrease in total time and cost and improve NPV. In this study, various solution methods of the cooperative game theory were used to solve the problem of determining the share of the participating contractors from this improvement.

In order to model this problem, a Multimode Resource-Constrained Project Scheduling Problem with Discounted Cash flows (MRCPSPDC) for each coalition was taken into account and a MixedInteger Nonlinear Programming (MINLP) model was developed. The suggested model can be used by partnering contractors to manage renewable resources more efficiently on a cooperative basis. In other words, partnering makes the feasible solution space of the problem larger and it can improve the solution.

Therefore, in the solution procedure, first, the suggested model was solved for all coalitions and then, the benefit (NPV) allocation problem was solved by 7 widely used cooperative game theory solution methods, namely Shapely value, $\tau$-value, average lexicographic value, equal split-off set, nucleolus, per-capita excess, and N-H solution. Eventually, the best allocation scheme based on the stability criteria of ShapleyShubik power index and $D P$ value was identified. 


\section{References}

1. Abeysekera, V. and McLean, C. "Project success and relationships from a stakeholder perspective: a pilot study", In Proceedings 17th Annual ARCOM Conference, pp. 5-7 (2001).

2. Nobbs, H., Future Role of Construction Specialists, London: Business Round Table (1993).

3. Kumaraswamy, M.M. and Matthews, J.D. "Improved subcontractor selection employing partnering principles", Journal of Management in Engineering, 16(3), pp. $47-57$ (2000).

4. Hartmann, A., Ling, F.Y.Y., and Tan, J.S. "Relative importance of subcontractor selection criteria: evidence from Singapore", Journal of Construction Engineering and Management, 135(9), pp. 826-832 (2009).

5. Humphreys, P., Matthews, J., and Kumaraswamy, M. "Pre-construction project partnering: from adversarial to collaborative relationships", Supply Chain Management: An International Journal, 8(2), pp. 166-178 (2003).

6. Bygballe, L.E., Jahre, M., and Swärd, A. "Partnering relationships in construction: A literature review", Journal of Purchasing and Supply Management, 16(4), pp. 239-253 (2010).

7. Dewulf, G. and Kadefors, A. "Collaboration in public construction contractual incentives, partnering schemes and trust", Engineering Project Organization Journal, 2(4), pp. 240-250 (2012).

8. Phua, F.T., and Rowlinson, S. "How important is cooperation to construction project success? A grounded empirical quantification", Engineering, Construction and Architectural Management, 11(1), pp. 45-54 (2004).

9. Chan, A.P., Chan, D.W., Chiang, Y.H., Tang, B.S., Chan, E.H., and Ho, K.S. "Exploring critical success factors for partnering in construction projects", Journal of Construction Engineering and Management, 130(2), pp. 188-198 (2004).

10. Perng, Y.H., Chen, S.J., and Lu, H.J. "Potential benefits for collaborating formwork subcontractors based on co-operative game theory", Building and Environment, 40(2), pp. 239-244 (2005).

11. Asgari, M.S. and Afshar, A. "Modeling sub-contractors cooperation in time; cooperative game theory approach", In First International Conference on Construction in Developing Countries (ICCIDC-I), pp. 312-319 (2008).

12. Barough, A.S., Shoubi, M.V., and Skardi, M.J.E. "Application of game theory approach in solving the construction project conflicts", Procedia-Social and Behavioral Sciences, 58, pp. 1586-1593 (2012).

13. Tsai, J.S. and Chi, C.S. "Learning for win-win collaboration", Journal of Construction Engineering and Management, 141(7), p. 04015013 (2015).
14. Asgari, S., Afshar, A., and Madani, K. "Cooperative game theoretic framework for joint resource management in construction", Journal of Construction Engineering and Management, 140(3), p. 04013066 (2013).

15. Samsami, R. and Tavakolan, M. "A game theoretic model for subcontractors' partnership in construction: Win-win game", In Construction Research Congress, pp. 597-606 (2016).

16. Arashpour, M., Wakefield, R., Lee, E., Chan, R., and Hosseini, M. "Analysis of interacting uncertainties in on-site and off-site activities: Implications for hybrid construction", International Journal of Project Management, 34, pp. 1393-1402 (2016).

17. Bredillet, C.N. "Learning and acting in project situations through a meta-method (MAP) a case study: contextual and situational approach for project management governance in management education", Int. J. Proj. Manag, 26 (3), pp. 238-250 (2008).

18. Herroelen, W., Van Dommelen, P., and Demeulemeester, E. "Project networks with discounted cash flows: A guided tour through recent developments", European Journal of Operational Research, 100, pp. 97-121 (1997).

19. Herroelen, W., De Reyck, B., and Demeulemeester, E. "Resource-constrained project scheduling: A survey of recent developments", Computers and Operations Research, 25, pp. 279-302 (1998).

20. Herroelen, W., Demeulemeester, E., and De Reyck, B. "A classification scheme for project scheduling", In J. Weglarz (Ed.), Project scheduling - Recent models, algorithms and applications, International Series in Operations Research and Management Science, 14, pp. 77-106. Boston: Kluwer Academic Publishers (1999).

21. Kolisch, R. and Hartmann, S. "Experimental investigation of heuristics for resource-constrained project scheduling: An update", European Journal of Operational Research, 174(1), pp. 23-37 (2006).

22. Hartmann, S. and Briskorn, D. "A survey of variants and extensions of the resource-constrained project scheduling problem", European Journal of Operational Research, 207, pp. 1-14 (2010).

23. Yang, K.K., Talbot, F.B., and Patterson, J.H. "Scheduling a project to maximize its net present value: an integer programming approach", European Journal of Operational Research, 64(2), pp. 188-198 (1993).

24. Vanhoucke, M., Demeulemeester, E., and Herroelen, W. "On maximizing the net present value of a project under renewable resource constraints", Management Science, 47(8), pp. 1113-1121 (2001).

25. Vanhoucke, M. "A scatter search procedure for maximizing the net present value of a resource-constrained project with fixed activity cash flow", International Journal of Production Research, 48(7), pp. 1983-2001 (2010). 
26. Khoshjahan, Y., Najafi, A.A., and Afshar-Nadjafi, B. "Resource constrained project scheduling problem with discounted earliness-tardiness penalties: Mathematical modeling and solving procedure", Computers \& Industrial Engineering, 66(2), pp. 293-300 (2013).

27. Leyman, P. and Vanhoucke, M. "Payment models and net present value optimization for resource-constrained project scheduling", Computers \& Industrial Engineering, 91, pp. 139-153 (2016).

28. Von Neumann, J. and Morgenstern, O., Theory of Games and Economic Behavior, Princeton University Press (2007).

29. Myerson, R.B. Effectiveness of Electoral Systems for Reducing Government Corruption: A Game-Theoretic Analysis, Center for Mathematical Studies in Economics and Management Science, Northwestern University (1991).

30. Cano-Berlanga, S., Giménez-Gómez, J.M., and Vilella, C. "Enjoying cooperative games: The $\mathrm{R}$ package game theory", Applied Mathematics and Computation, 305, pp. 381-393 (2017).

31. Branzei, R., Dimitrov, D., and Tijs, S. Models in Cooperative Game Theory, Springer Science \& Business Media (2008).

32. Shapley, L.S. "A value for n-person games", Contributions to the Theory of Games, 2(28), pp. 307-317 (1953).

33. Tijs, S.H. "Bounds for the core and the $\tau$-value", Game Theory and Mathematical Economics, O. Moeschlin and D. Pallaschke, Eds., North-Holland Publishing Company, Amsterdam, pp. 123-132 (1981).

34. Tijs, S.H. "The first steps with Alexia, the average lexicographic value", CentER Discussion Paper, 123, Tilburg University (2005).

35. Branzei, R., Dimitrov, D., and Tijs, S. "The equal split-off set for cooperative games", Banach Center Publications, 71, pp. 39-46 (2006).

36. Schmeidler, D. "The nucleolus of a characteristic function game", SIAM Journal on Applied Mathematics, 17(6), pp. 1163-1170 (1969).

37. Wu, Q., Ren, H., Gao, W., and Ren, J. "Benefit allocation for distributed energy network participants applying game theory based solutions", Energy, 119, pp. 384-391 (2017).
38. Guajardo, M. and Jörnsten, K. "Common mistakes in computing the nucleolus", European Journal of Operational Research, 241(3), pp. 931-935 (2015).

39. Perng, Y.H., Chen, S.J., and Lu, H.J. "Potential benefits for collaborating formwork subcontractors based on co-operative game theory", Building and Environment, 40(2), pp. 239-244 (2005).

40. Dinar, A. and Howitt, R.E. "Mechanisms for allocation of environmental control cost: empirical tests of acceptability and stability", Journal of Environmental Management, 49(2), pp. 183-203 (1997).

41. Fromen, B. "Reducing the number of linear programs needed for solving the nucleolus problem of n-person game theory", European Journal of Operational Research, 98(3), pp. 626-636 (1997).

42. Shapley, L.S. and Shubik, M. "A method for evaluating the distribution of power in a committee system", American Political Science Review, 48(3), pp. 787-792 (1954).

43. Loehman, E., Orlando, J., Tschirhart, J., and Whinston, A. "Cost allocation for a regional wastewater treatment system", Water Resources Research, 15(2), pp. 193-202 (1979).

44. Williams, M.A. "An empirical test of cooperative game solution concepts", Systems Research and Behavioral Science, 33(3), pp. 224-237 (1988).

45. Gately, D. "Sharing the gains from regional cooperation: A game theoretic application to planning investment in electric power", International Economic Review, pp. 195-208 (1974).

\section{Biography}

Mahdieh Akhbari received her BSc degree from K.N. Toosi University of Technology in 2004, MS degree from Isfahan University of Technology in 2007, and $\mathrm{PhD}$ degree from Islamic Azad University, Science and Research Branch, in 2014 all in Industrial Engineering. She is currently Assistant Professor in the Industrial Engineering Department of the Electronic Branch of the Islamic Azad University. Her research interests include soft computing, game theory, and mathematical modeling. 